\title{
An effective device for generating alginate microcapsules
}

Tatiana A.B. Bressel ${ }^{1,2}$, Ana Helena Paz ${ }^{3}$, Guilherme Baldo ${ }^{4}$, Elizabeth O. Cirne Lima ${ }^{5}$, Ursula Matte ${ }^{4}$ and Maria Luiza Saraiva-Pereira ${ }^{2,6,7}$

${ }^{1}$ Departamento de Genética, Universidade Federal do Rio Grande do Sul, Porto Alegre, RS, Brazil.

${ }^{2}$ Serviço de Genética Médica, Hospital de Clínicas de Porto Alegre, RS, Brazil.

${ }^{3}$ Departamento de Gastroenterologia, Universidade Federal do Rio Grande do Sul, Porto Alegre,

RS, Brazil.

${ }^{4}$ Centro de Terapia Gênica, Centro de Pesquisas, Hospital de Clínicas de Porto Alegre, Porto Alegre, RS, Brazil.

${ }^{5}$ Departamento de Patologia Veterinária, Universidade Federal do Rio Grande do Sul, Porto Alegre, RS, Brazil.

${ }^{6}$ Laboratório de Identificação Genética, Centro de Pesquisas, Hospital de Clínicas de Porto Alegre, Porto Alegre, RS, Brazil.

${ }^{7}$ Departamento de Bioquímica, Universidade Federal do Rio Grande do Sul, Porto Alegre, RS, Brazil.

\begin{abstract}
An alternative approach to somatic gene therapy is to deliver the therapeutic protein by implanting genetically modified cells that could overexpress the gene of interest. Microencapsulation devices were designed to protect cells from host rejection and prevent the foreign cells from spreading while allowing protein secretion. Alginate microcapsules form a semi-permeable structure that is suitable for in vivo injection. In this study, we report an effective laboratory protocol for producing calcium alginate microcapsules, following optimization of uniformly shaped and sized particles containing viable cells. Encapsulation of baby hamster kidney (BHK) cells in alginate microcapsules was performed using a simple device consisting of a cylinder of compressed air and a peristaltic pump. A cell suspension flow of $100 \mathrm{~mL} \mathrm{~h}^{-1}$ and an air jet flow of $10 \mathrm{~L} \mathrm{~min}^{-1}$ produced the best uniformity of microcapsule size and shape. Cells maintained viability in culture for 4 weeks without any signs of necrosis, and protein diffusion was observed during this period. Our results clearly demonstrated that microisolation of BHK cells in alginate using a simple assembly device could provide an environment that is capable of preserving live cells. In addition, encapsulated cells under the conditions described were able to secrete an active enzyme even after four weeks, thus becoming potentially compatible with therapeutic protein delivery.
\end{abstract}

Key words: Alginate, beads, controlled release, drug delivery, microcapsules.

Received: May 9, 2007; Accepted: July 17, 2007.

\section{Introduction}

An alternative approach to cell therapy and somatic gene therapy is to deliver therapeutic proteins by implanting genetically modified cells that could overexpress a gene of interest. This is usually achieved by transducing stable cell lines. These cells are immortal and can sustain protein synthesis for long periods, if adequate transgenes are used. The problem is graft rejection in non-autologous transplantation and the tumorigenic potential of such cells (Babensee et al., 1998).

Send correspondence to Maria Luiza Saraiva-Pereira. Serviço de Genética Médica, Hospital de Clínicas de Porto Alegre, Rua Ramiro Barcelos 2350, 90035-903 Porto Alegre, RS, Brazil. E-mail: mlpereira@hcpa.ufrgs.br.
In order to solve these problems, it is important to design microencapsulation devices to protect cells from host rejection and prevent tumor spread while allowing protein secretion. This potentially cost-effective method of in vivo heterologous protein delivery has been used in many studies (Bachoud-Levi et al., 2000; Barsoum et al., 2003; Friso et al., 2005; Dusseault et al., 2005).

Whole cell immobilization by entrapment is a widely used, simple technique. Matrices of different polysaccharides, such as calcium alginate or chitosan, among others, appear to be a promising alternative for improving drug delivery (Janes et al., 2001; Adinarayana et al., 2005; Kim et $a l ., 2005)$, the most widely used encapsulation compound being sodium alginate (Weber et al., 2004). 
Unlike most other polysaccharide gels, alginate gels can form and set at constant temperature, this unique property being particularly useful in applications involving fragile materials such as cells or tissue that have a low tolerance for high temperatures (Martinsen et al., 1989). Alginate also has some useful pharmaceutical characteristics, especially the formation of a net-like lattice between cations and alginate in the gel which is responsible for the slow release of embedded drugs. This property can be useful for the development of alginate-based drug delivery systems (Kim et al., 2005; Murata et al., 2004).

Derived from brown algae and bacteria, alginates are a family of unbranched polysaccharides with properties that vary widely depending on their composition (Keshaw et al., 2005). Alginates are copolymers of $\beta$-D-mannuronic acid (M) and $\alpha$-L-guluronic acid (G), which are able to function as thermally stable gelling agents. Monomers can appear in homopolymeric blocs of consecutive G-residues (G-blocks), consecutive M-residues (M-blocks), alternating $\mathrm{M}$ and $\mathrm{G}-$ residues (MG-blocks) or randomly organized blocks. With divalent cations such as $\mathrm{Ca}^{2+}, \mathrm{Ba}^{2+}, \mathrm{Sr}^{2+} \mathrm{G}-$ blocks form stable cross-linked junctions leading to a three-dimensional gel network. Gel formation occurs when divalent cations take part in interchain ionic binding between guluronic acid blocks (G-blocks) in the polymer chain, giving rise to a three dimensional network. Such binding zones between the G-blocks are often referred to as "egg-boxes" (Simpson et al., 2003). This leads to a semipermeable structure in which encapsulated cells are protected against exposure to the host's immune system while the influx of oxygen and nutrients and the release of therapeutic proteins is allowed. Such particles allow highdensity in vitro cell culture, and are suitable for in vivo intra-tissue injection (Fiszman et al., 2002).

Cells immobilized in alginate gels are viable during long-term culture due to the mild environment of the gel network. For most uses, and in particular those involving immobilization of living cells, microcapsules are used because particles $<1 \mathrm{~mm}$ in diameter are less fragile than other sizes and have a high surface to volume ratio which allows good diffusion of oxygen an essential nutrients which may be limited in larger particles. At this microcapsule size, these substances do not reach the core and cause cell death because they are used to nourish peripheral cells.

Since microcapsule size and shape are crucial and must be carefully controlled suitable methodology is needed to produce small microcapsules under controlled conditions. The large-scale applicability of such techniques requires cost-effective and reliable microencapsulation methods. Optimization of alginate microcapsule production in terms of shape and size uniformity is also crucial in research protocols.

In this paper we report the optimization of a costeffective protocol for generating calcium alginate micro- capsules of a uniform shape and size containing viable cells and evaluate cell viability, alginate toxicity and protein diffusion rate.

\section{Material and Methods}

\section{Cell culture}

Baby hamster kidney (BHK) cells (CCL-10, American Type Culture Collection (ATCC; Rockville, MD, USA)), obtained from the Rio de Janeiro Cell Bank, were cultured as a monolayer in $T 25$-ml flasks at $37^{\circ} \mathrm{C}$ and $5 \%$ (v/v) $\mathrm{CO}_{2}$ in Dulbecco's Modified Eagle's Medium (D-MEM; GIBCO, USA) supplemented with 10\% (v/v) fetal bovine serum (FBS; CULTILAB, Campinas, SP, Brazil). Serial runs were made using trypsin (1 $\mathrm{g}$ trypsin in $250 \mathrm{~mL}$ PBS and $0.02 \%$ (w/v) EDTA (GIBCO, USA)) every 2-3 days. For preparation of microencapsulated cells, BHK cells were harvested from monolayer cultures using trypsin-EDTA and then resuspended at a final concentration of $1 \times 10^{5}$ cells mL $\mathrm{mL}^{-1}$ in D-MEM containing $1.5 \%(\mathrm{w} / \mathrm{v})$ low viscosity sodium alginate (Sigma).

\section{Device assembly and cell encapsulation}

An effective device assembled in our laboratory produce air-jet droplet generation using a compressed air cylinder equipped with a flow meter connected to a PVC tubing of $80 \mathrm{~cm}$ into which a 25 -gauge stainless steel injection needle was inserted in the end of this tubing at a $45^{\circ}$ angle until the tip reached the lumen. The needle was then connected to a model EQL P parenteral administration set (LIFEMED, São Paulo, Brazil) which was attached to a model LF2001 peristaltic pump (LIFEMED, São Paulo, Brazil) and finally to a Viaflex intravenous solution bag (catalogue number AZB1322, Baxter, USA) containing the BHK cells alginate mixture described, the bag being placed $50 \mathrm{~cm}$ above the peristaltic pump and the cell suspension dispensed at different flow rates by the pump. Airflow was also variable during the experiments. A beaker containing $125 \mathrm{mM} \mathrm{CaCl}_{2}$ solution was placed $3 \mathrm{~cm}$ below the tip of the needle so that alginate microcapsules were formed immediately after the alginate cell suspension dropping into the $\mathrm{CaCl}_{2}$ solution in the beaker. The whole system, except the compressed air cylinder, was assembled inside a laminar flow hood to ensure sterility (Figure 1). We tested air-flow rates of $5 \mathrm{~L} \mathrm{~min}^{-1}, 10 \mathrm{~L} \mathrm{~min}^{-1}$ and $15 \mathrm{~L} \mathrm{~min}^{-1}$ and peristaltic pump rates 100 and $180 \mathrm{~mL} \mathrm{~h}^{-1}$. The alginate microcapsules containing the BHK cells were gently washed twice with purified water (Mili-Q, USA) and transferred to 6-well microtiter plates (Techno Plastic Produts, Switzerland) containing sufficient D-MEM supplemented with $10 \%$ FBS to cover the microcapsules and incubated for 28 days weeks under the culture conditions described above, changing the culture medium every 2 days.

The microcapsules were examined with a magnifying glass and measured with a pachymeter and cell viability 


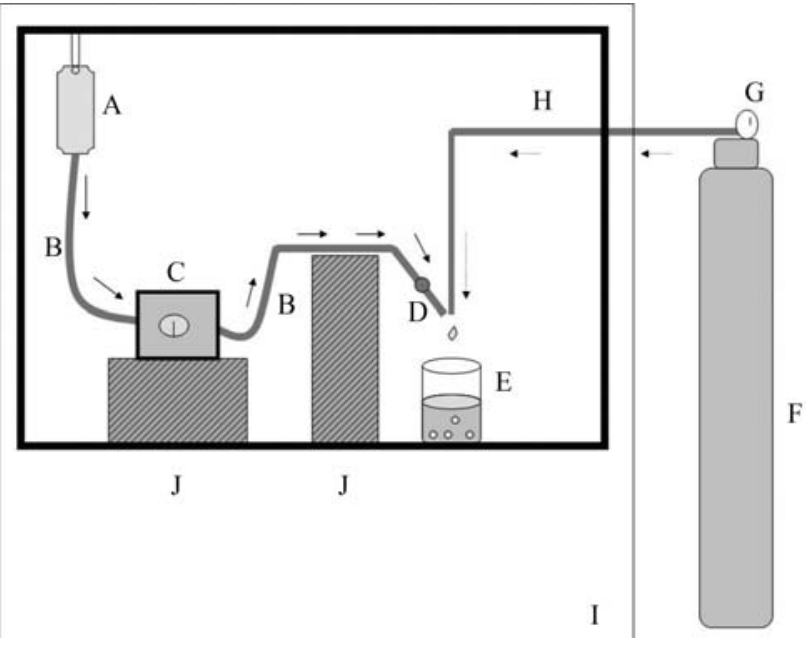

Figure 1 - Diagram of the microcapsule generator. a) Viaflex bag containing low viscosity Dulbecco's Modified Eagle's Medium (D-MEM) supplemented with $1.5 \%(\mathrm{w} / \mathrm{v})$ sodium alginate containing baby hamster kid-

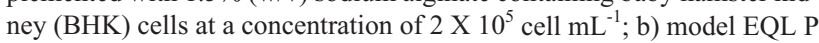
parenteral pump; c) model LF2001 volumetric infusion pump; d) 25 gauge needle; e) beaker containing $125 \mathrm{mM} \mathrm{CaCl}_{2}$ solution; f) compressed air cylinder; g) flow meter; h) $80 \mathrm{~cm}$ PVC tubing; i) laminar flow hood; and j) support.

was determined using the trypan blue exclusion method (Seth et al., 2004). Every seven days microcapsules from 3 wells were collected and separated from the culture medium by centrifugation at $500 \mathrm{~g} \mathrm{~min}^{-1}$ for $3 \mathrm{~min}$. After centrifugation, the cells were resuspended in one $\mathrm{mL}$ of $40 \mathrm{mM}$ sodium citrate solution and then re-precipitated by centrifugation at $500 \mathrm{~g} \mathrm{~min}^{-1}$ for $3 \mathrm{~min}$. Cells were then stained with trypan blue solution, and counted in a Neubauer chamber. Cell viability was estimated by comparing the number of live cells to the total number of cells and results expressed as the percentage of viable cells.

\section{Assessment of protein diffusion}

Since BHK cells produce $\beta$-galactosidase we evaluated protein diffusion by measuring the activity of this enzyme in the culture medium from 3 different wells every seven days for 28 days using the artificial substrate 4methylumbelliferyl $\beta$-d-galactoside (MUG) and measuring the fluorescence produced in F-2000 spectrofluorometer (Hitachi, Japan) using a $355 \mathrm{~nm}$ excitation filter and a $460 \mathrm{~nm}$ emission filter (Suzuki, 1977).

\section{Results}

The cross-linked alginate polysaccharide polymers formed solid spherical microcapsules containing embedded cells. As also observed by Fiszman et al. (2002), microcapsule diameter decreased with increasing air flow (Figure 2) and the shape of the microcapsules changed with the peristaltic pump rate, flow rates of $100 \mathrm{~mL} \mathrm{~h}^{-1}$ producing uniform solid spherical microcapsules containing embedded cells.

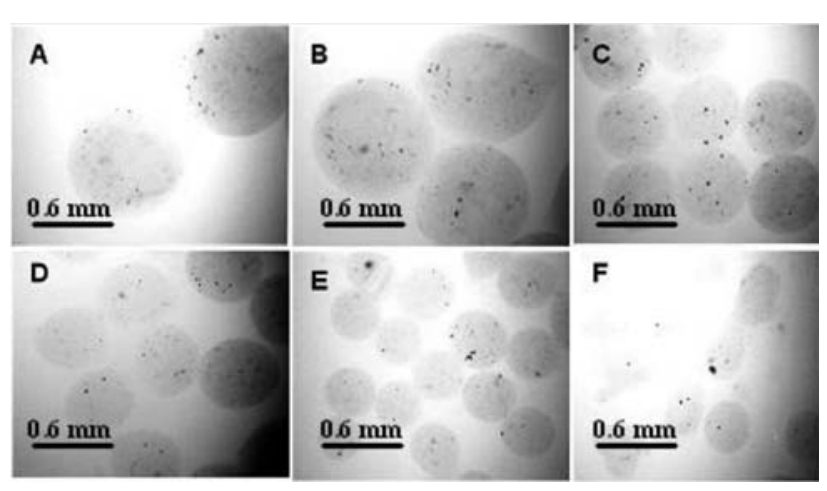

Figure 2 - Shape and size of particles obtained with different air jet flows and peristaltic pump rates. a) $1.15 \mathrm{~mm} \pm 0.05 \mathrm{~mm}$ microcapsules, airflow $5 \mathrm{~L} \mathrm{~min}^{-1}$, peristaltic flow rate $100 \mathrm{~mL} \mathrm{~h}^{-1}$; b) $1.15 \mathrm{~mm} \pm 0.05 \mathrm{~mm}$ microcapsules, airflow $5 \mathrm{~L} \mathrm{~min}^{-1}$, peristaltic pump rate $180 \mathrm{~mL} \mathrm{~h}^{-1}$; c) $0.6 \mathrm{~mm} \pm 0.05 \mathrm{~mm}$ microcapsules, airflow $10 \mathrm{~L} \mathrm{~min}^{-1}$, peristaltic pump rate $100 \mathrm{~mL} \mathrm{~h}^{-1}$; d) $0.6 \mathrm{~mm} \pm 0.05 \mathrm{~mm}$ microcapsules, airflow $10 \mathrm{~L} \mathrm{~min}^{-1}$, peristaltic pump rate $180 \mathrm{~mL} \mathrm{~h}^{-1}$; e) $0.4 \mathrm{~mm} \pm 0.05 \mathrm{~mm}$ microcapsules, airflow $15 \mathrm{~L} \mathrm{~min}^{-1}$, peristaltic pump rate $100 \mathrm{~mL} \mathrm{~h}^{-1}$; and f) $0.4 \mathrm{~mm} \pm$ $0.05 \mathrm{~mm}$ microcapsules, airflow $15 \mathrm{~L} \mathrm{~min}^{-1}$ peristaltic pump rate $180 \mathrm{~mL} \mathrm{~h}^{-1}$.

We successfully obtained microcapsules with a diameter smaller than $1 \mathrm{~mm}$, the smallest diameter microcapsules $(0.4 \mathrm{~mm} \pm 0.05 \mathrm{~mm})$ being produced at an air flow rate of $15 \mathrm{~L} \mathrm{~min}{ }^{-1}$, medium-sized microcapsules $(0.6 \mathrm{~mm} \pm 0.05 \mathrm{~mm})$ at an air flow of $10 \mathrm{~L} \mathrm{~min}^{-1}$ and the largest microcapsules $(1.15 \mathrm{~mm} \pm 0.05 \mathrm{~mm})$ at an air flow of $5 \mathrm{~L} \mathrm{~min}{ }^{-1}$.

Cells were incorporated into the alginate microcapsules as shown by Figure 3. As assessed by the trypan blue exclusion assay, encapsulated cells remained viable in culture for 28 days and no signs of necrosis were seen in the microcapsules during this time. There is no significant change in the shape of the microcapsules during the experiment, long-lasting gel integrity being critical to prolong the control of cell growth.

Cell viability was evaluated every seven days, the results being shown in Figure 4. During the 28 days of the experiment cell viability remained above $90 \%$. Moreover, the total number of cells increased during the experiment, indicating that the cells were replicating inside the alginate microcapsules.

Protein diffusion was estimated by comparing the number of cells to the $\beta$-galactosidase activity released into the culture medium (Figure 4 ). We found that, for comparable numbers of cells, the rate of $\beta$-galactosidase synthesis was lower $\left(0.7 \mathrm{nmol} \mathrm{h}^{-1} \mathrm{~mL}^{-1}\right)$ for encapsulated cells than for free cells $\left(14.5 \mathrm{nmol} \mathrm{h}^{-1} \mathrm{~mL}^{-1}\right)$. As the number of cells increased, so did the protein activity detected in the medium, probably reflecting an increase in the amount of protein secreted.

\section{Discussion}

We presented an efficient method to microencapsulate cultured cells using equipment and disposable 


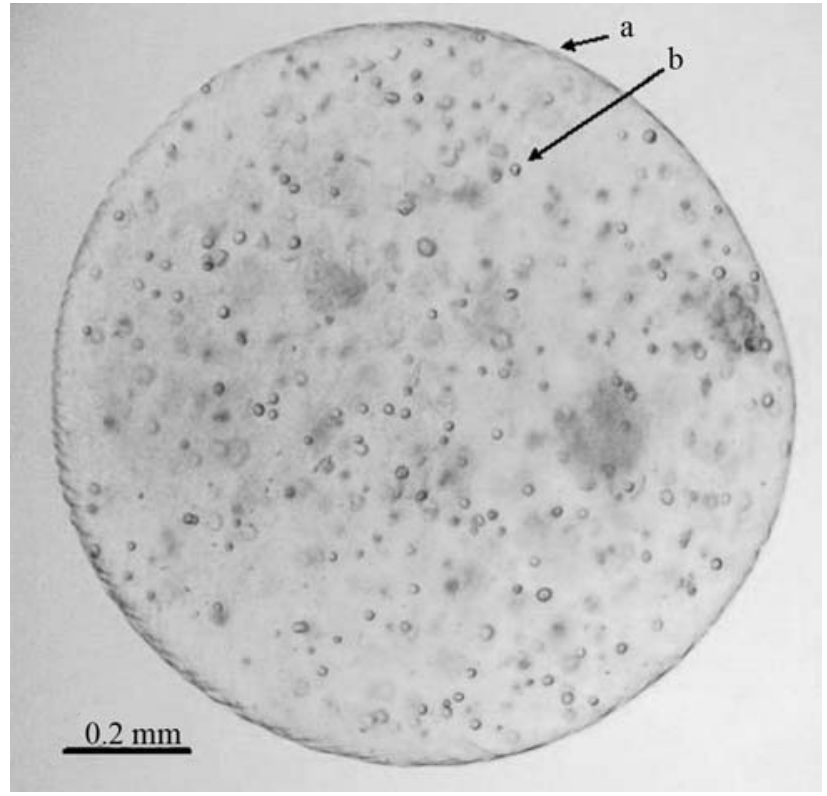

Figure 3 - Microcapsule containing baby hamster kidney (BHK) cells maintained in vitro for 4 weeks. a) alginate gel; b) BHK cells.

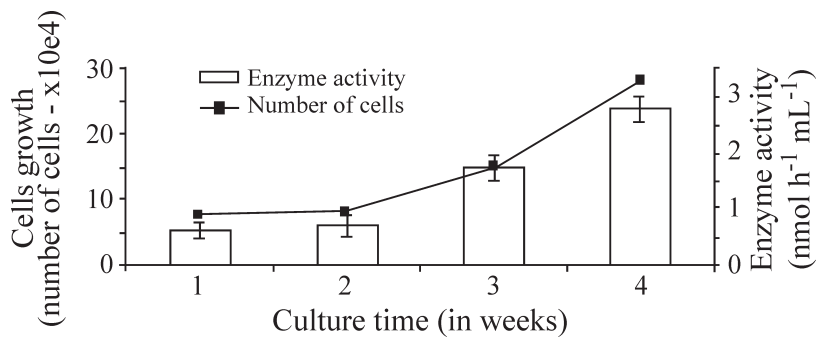

Figure 4 - Cell count for encapsulated baby hamster kidney (BHK) and $\beta$-galactosidase activity in the culture medium. The cells were encapsulated using an airflow of $15 \mathrm{~L} \mathrm{~min}^{-1}$ and a peristaltic pump rate of $100 \mathrm{~mL} \mathrm{~h}^{-1}$ to produce a microcapsule size of $0.4 \mathrm{~mm} \pm 0.05 \mathrm{~mm}$.

supplies normally available in a molecular biology or biochemistry laboratory. A key difference between the microencapsulation method presented here and those previously published (Simpson et al., 2003; Weber et al., 2004; Dusseault et al., 2005; and others) is cost-effectiveness, since it is unnecessary to acquire a special device to prepare the microcapsules. Generally, low-price devices for producing cells encapsulated in alginate can cost at least five times more than the amount spent for the device outlined in this study.

Comparing the device described here to that described by Fiszman et al. (2002), our device does not use the half-blister chamber and thus generates more uniform microcapsules. A half-blister chamber allows the formation of circular laminar flow or turbulence and produces irregular droplets due to the larger diameter of the half-blister chamber compared to air tubing, creating transient lowpressure zones and a decrease in linear air speed. Under these conditions, airflow changes course in the direction of lower pressure areas inducing the formation of circular laminar flow or even turbulence. The phenomena involving turbulent flow are generally described by the complex Navier-Stokes equation (Riley, 2006). Considering the production of more uniform microcapsules, the best results in our study were obtained by introducing the needle at a $45^{\circ}$ angle into the air tubing.

Another important feature is the use of a compressed air cylinder instead of an air compressor. Airflow is more uniform when using a compressed air cylinder because the air is affected by the internal pressure inside the cylinder and flow is regulated by a flow meter and thus provides a uniform flow rate, whereas air compressors use intermittent power and produce less uniform flow.

The methodology described in this paper was able to generated encapsulated BHK cells that produced $\beta$-galactosidase within the microcapsules, the enzyme being able to cross the lattice network of the gel as evidenced by the enzyme activity detected in the culture medium.

In most applications involving immobilization of live cells or other biological materials, microcapsule shape and size are critical. Encapsulating cells in small-diameter microcapsules is useful in reduce mass transfer resistance caused by the encapsulation material, allowing greater oxygen and nutrient availability for cells located inside the microcapsules. Furthermore, producing correctly-shaped uniform microcapsules is essential to guarantee gelling uniformity and thus avoid incomplete alginate gel formation (Keshaw et al., 2005).

In this paper we have reported an effective laboratory method for generating calcium alginate microcapsules and the optimization of microcapsule generation to obtain particles with of a uniform shape and size containing viable BHK cells. The results of these in vitro studies clearly demonstrate that micro isolation of BHK cells in alginate using a simple assembly device can provide an environment that is compatible with the maintenance of viable cells.

Although further long-term studies need to be carried out, our experiments proved to be an effective, reliable and cost-effective methodology for producing calcium alginate microcapsules containing cells. It may also be possible to modify the methodology for other applications and can be easily and widely employed by research groups worldwide.

\section{Acknowledgments}

We are grateful to LIFEMED for technical assistance, and for supplying a volumetric infusion pump LF2001 and administration sets. This work was supported by the Brazilian agencies CNPq, SCT-RS and FIPE/HCPA.

\section{References}

Adinarayana K, Jyothi B and Ellaiah P (2005) Production of akaline protease with immobilized cells of Bacillus subtilis 
PE-11 in various matrices by entrapment technique. AAPS Pharm Sci Tech 6:E391-E397.

Babensee JE, Anderson JM, McIntire LV and Mikos AG (1998) Host response to tissue engineered devices. Adv Drug Del Rev 33:111-139.

Bachoud-Levi AC, Deglon N, Nguyen JP, Bloch J, Bourdet C, Winkel L, Remy P, Goddard M, Lefaucheur JP, Brugieres P et al. (2000) Neuroprotective gene therapy for Huntington's disease using a polymer encapsulate BHK cell line engeneered to secret human CNTF. Hum Gen Ther 11:17231732.

Barsoum SC, Milgram W, Mackay W, Coblentz C, Delaney KH, Kwiecien JM, Kruth S and Chang PL (2003). Delivery of recombinant gene product to canine brain with the use of microencapsulation. J Lab Clin Med 142:399-413.

Dusseault J, Leblond FA, Robitaille R, Jourdan G, Tessier J, Ménard M, Henley N and Hallé JP (2005) Microencapsulation of living cells in semi-permeable membranes with covalently cross-linked layers. Biomaterials 26:15151522 .

Fiszman GL, Karara AL, Finocchiaro LME and Glikin GC (2002) A laboratory scale device for microencapsulation of genetically engineered cells into alginate beads. Electron J Biotechnol 5:23-24.

Friso A, Tomanin R, Alba S, Gasparotto N, Puicher EP, Fusco M, Hortelano G, Muenzer J, Marin O, Zacchello F et al. (2005) Reduction of GAG storage in MPS II mouse model following implantation of encapsulated recombinant myoblasts. J Gene Med 7:1482-1491.

Janes KA, Calvo P and Alonso MJ (2001) Polysaccharide colloidal particles as delivery systems for macromolecules. Adv Drug Deliv Rev 47:83-97.
Keshaw H, Forbes A and Day RM (2005) Release of angiogenic growth factors from cells encapsulated in alginate beads with bioactive glass. Biomaterials 26:4171-4179.

Kim YJ, Park HG, Yang YL, Yoon Y, Kim S and Oh E (2005) Multifuncional drug delivery system using starch-alginate beads for controlled release. Biol Pharm Bull 28:394-397.

Martinsen A, Jinno D, Kofuji K and Kawashima S (1989) Alginate as immobilization material: I Correlations between chemical and physical properties of alginate beads. Biotechnol Bioeng 33:79-89.

Murata Y, Jinno D, Kofuji K and Kawashima S (2004) Properties of calcium-induced gel beads prepared with alginate and hydrolysates. Chem Pharm Bull 52:605-607.

Riley N (2006) The Navier-Stokes Equations: A Classification of Flows and Exact Solutions. Cambridge University Press, Cambridge, 196 pp.

Seth R, Yang S, Choi S, Sabean M and Roberts EA (2004) In vitro assessment of copper-induced toxicity in the human hepatoma line, Hep G2. Toxicol In Vitro 18:501-509.

Simpson NE, Grant SC, Blackband SJ and Constantinidis I (2003) NMR properties of alginate microbeads. Biomaterials 24:4941-4948.

Suzuki K (1977) Globoid cell leukodystrophy (Krabbe disease) and GM1 gangliosidosis. In: Glew RH and Peters SP (eds) Pratical Enzymology of the Sphingolipidoses. Alan R. Liss, New York, pp 101-136.

Weber W, Rinderknecht M, Baba MD, Glutz FN, Aubel D and Fussenegger M (2004) CellMAC: A novel technology for encapsulation of mammalian cells in cellulose sulfate/ pDADMAC capsules assembled on a transient alginate $/ \mathrm{Ca}^{2+}$ scaffold. J Biotechnol 114:315-326.

Associate Editor: Carlos F.M. Menck 